Revista de Economia Política, vol. 29, $n^{\circ} 3$ (115), pp. 274-294, julho-setembro/2009

\title{
A arquitetura do sistema financeiro internacional contemporâneo
}

\author{
MARYSE FARHI \\ MARCOS ANTONIO MACEDO CINTRA*
}

The architecture of the current international financial system. This paper discusses some features of financial institutions and instruments which originated the financial crisis triggered by increasing default rate, household real estate and financial asset depreciation combined with U.S. subprime mortgages. The first part presents major crisis events in a chronological order. The second part describes the interconnection of the institutions and markets which engendered a global shadow financial system. The third part focuses on an overview of measures taken by government authorities and large banks to bring about possible solutions for the global financial crisis.

Keywords: financial crisis; banks; mortgages; investment banks; ratings agencies. JEL Classification: G01; G21; G24.

\section{INTRODUÇÃO}

A crise financeira iniciada nos Estados Unidos, em meados de 2007, em decorrência da forte elevação da inadimplência e da desvalorização dos ativos associados com hipotecas de alto risco (subprime), tem renovado os questionamentos sobre a arquitetura contemporânea do sistema financeiro americano e internacional, seus potenciais riscos sistêmicos e seus mecanismos de supervisão e regulação. Essa

\footnotetext{
* Professora do Instituto de Economia da Universidade Estadual de Campinas (Unicamp) e pesquisadora do Centro de Conjuntura e Política Econômica (Cecon/IE/Unicamp); Professor do IE/Unicamp e pesquisador do Conselho Nacional de Desenvolvimento Científico e Tecnológico (CNPq). Artigo elaborado com informações disponíveis até primeira quinzena de abril de 2009. Os autores agradecem os comentários de Ricardo Carneiro, Antonio C. M. e Silva, Daniela Prates, Francisco Lopreato, André Biancareli, Emerson Marçal, Eliana Ribeiro, Cristina Penido, José Carlos Braga, Rafael Cagnin e André Scherer.
} 
arquitetura específica transformou uma crise de crédito clássica em uma crise financeira e bancária de grandes proporções. Numa crise de crédito clássica, o somatório dos prejuízos potenciais (correspondente aos empréstimos concedidos com baixo nível de garantias) já seria conhecido. $\mathrm{Na}$ atual configuração dos sistemas financeiros, os derivativos de crédito e os produtos estruturados lastreados em crédito imobiliário multiplicaram tais prejuízos por um fator desconhecido e redistribuíram, globalmente, os riscos deles decorrentes para uma grande variedade de agentes. As próprias características dos mecanismos de transferência de riscos introduziram novas incertezas. Não se sabe se os riscos foram diluídos entre um grande número de pequenos especuladores ou se foram concentrados em algumas carteiras. Dessa forma, um ano e meio após a eclosão da crise, os prejuízos persistem incomensuráveis e sua distribuição continua em grande parte desconhecida, contribuindo para contrair o volume de crédito (credit crunch), manter elevadas as taxas de juros para empréstimo, acentuar a incerteza e, por vezes, o pânico entre os investidores, além de provocar o empoçamento da liquidez nos mercados interbancário.

Este artigo procura discutir algumas características das instituições e dos instrumentos financeiros que geraram tal crise. $\mathrm{O}$ artigo está organizado em três seções, após esta introdução. Na primeira seção, realiza-se uma pequena cronologia dos principais eventos da crise. Na segunda seção, efetua-se a caracterização dos principais elementos do global shadow banking system (sistema bancário global na sombra ou paralelo). Na terceira seção, delineia-se um panorama das ações implementadas pelas autoridades governamentais e pelos grandes bancos a fim de encaminhar possíveis soluções para a crise financeira global.

\section{O DESENROLAR DA CRISE FINANCEIRA}

A partir de junho de 2007, ocorreram diversos momentos mais agudos da crise, com repercussões acentuadas nos mercados interbancários globais ${ }^{1}$. Esses momentos ficam explícitos no comportamento da TED spread - a diferença entre a taxa de juros dos títulos do Tesouro americano de três meses (no mercado secundário) e a taxa Libor (London Interbank Offered Rate) para os depósitos em eurodólar de três meses -, referência internacional para empréstimos entre bancos (ver Gráfico 1). Apesar da acentuada queda da taxa básica de juros americana, o spread entre títulos de curto prazo do Tesouro e a Libor continuou superior ao constatado antes da eclosão da crise, demonstrando acentuada incerteza no mercado interbancário.

Em meados de junho de 2007, afloraram rumores de que dois hedge funds geridos pelo Bear Sterns, com ativos garantidos por hipotecas subprimes, tinham

\footnotetext{
${ }^{1}$ Para uma cronologia mais detalhada dos principais eventos da crise, ver BIS (2008, pp. 109-110), Borio (2008) e Fundap (2008).
} 
sofrido perdas e que o banco tinha vendido US\$ 3,8 bilhões em bônus para fazer frente às reposições de garantias. As agências de classificação de riscos começaram a rebaixar a classificação de títulos RMBS (Residential-Mortgage-Backed Securities), garantidos por hipotecas residenciais, e dos CDO (Collateralized debt obligation). No início de agosto de 2007, o BNP Paribas Investment Partners suspendeu os resgates e subscrições em três fundos de investimentos, após a reclassificação das notas de inúmeros ativos relacionados com as hipotecas americanas pelas agências de risco.

Gráfico 1: TED Spread - Prêmio de risco entre títulos de curto prazo americano e taxa Libor (pontos percentuais)

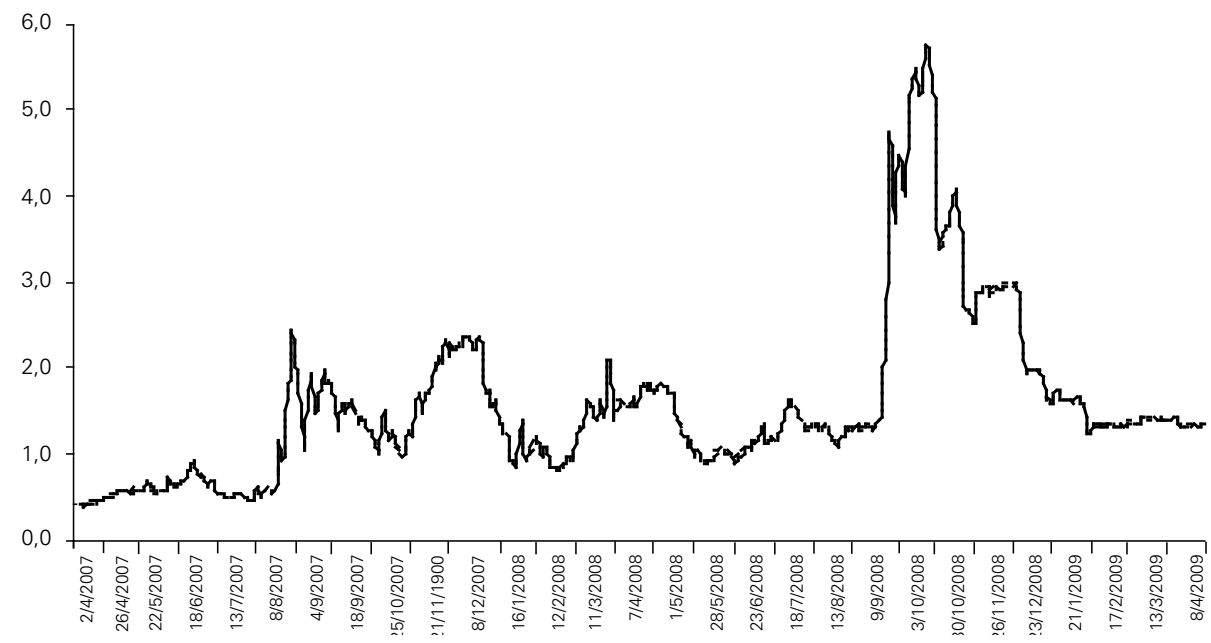

Fonte: Federal Reserve. Disponível em http://www.federalreserve.gov/releases/h15/data.htm. Nota: A TED spread é a diferença entre a taxa dos títulos do Tesouro americano de três meses (mercado secundário) e a Libor para os depósitos em eurodólar de três meses.

O Federal Reserve (Fed) e o Banco Central Europeu (BCE) realizaram amplas operações de ampliação da liquidez dos mercados. Ocorreram ainda a intervenção do Bundesbank no banco alemão IKB e a falência da American Home Mortgage Investment Corporation. No final de novembro e início de dezembro de 2007, diversos bancos americanos e europeus anunciaram planos de incorporar nos seus balanços ativos alocados em SIV (Special Investments Vehicles). Diante das expectativas de elevadas perdas a serem reveladas pelos balanços bancários, os bancos centrais dos EUA, Inglaterra, Europa, Suíça, Canadá, Japão e Suécia foram forçados a uma intervenção conjunta. Essa deterioração nas expectativas se prolongou durante o mês de janeiro de 2008, com a divulgação de novas perdas e o rebaixamento dos ratings das seguradoras monolines (tais como, Ambac, MBIA, Assured Guaranty, FSA), especializadas em fornecer garantias às emissões de bônus de Estados e Municípios americanos.

Em março de 2008, a falência do quinto maior banco de investimentos americano, o Bear Stearns, foi evitada pela intervenção e por garantias de US\$ 29 bi- 
lhões oferecidas pelo Fed para sua compra com grande desvalorização pelo JP Morgan Chase (US\$ 10 por ação, sendo que um ano antes a cotação havia alcançado US\$ 170). Enquanto banco de investimentos, o Bear Stearns não era supervisionado pelo Fed, nem tinha acesso às operações de redesconto ${ }^{2}$.

Em que pesem diversas declarações de que o pior da crise tinha passado, outros pontos de alta tensão voltaram a ocorrer. Em julho de 2008, ocorreu a falência do IndyMacBank, parte do conjunto de instituições financeiras do Federal Savings Bank (FSB), especializadas em crédito hipotecário. O IndyMacBank era o maior savings and loan na região de Los Angeles e o sétimo maior em concessão ("originador") de hipotecas dos Estados Unidos. A instituição sofreu intervenção do Federal Deposit Insurance Corp. (FDIC), fundo garantidor dos depósitos até US\$100 mil. Em decorrência do colapso do IndyMacBank, dois efeitos mais imediatos foram registrados: a) os depositantes no sistema bancário americano com depósitos superiores ao limite garantido pelo FDIC procuraram redistribuí-los entre diversos bancos; b) os temores de investidores e depositantes se alastraram para as demais instituições do FSB, provocando diversas novas falências ${ }^{3}$.

Quase ao mesmo tempo da falência do IndyMac, ocorreu uma acentuada perda de confiança nas duas grandes agências quase-públicas, criadas com o propósito de prover liquidez ao mercado imobiliário americano, a Federal National Mortgage Association (apelidada de Fannie Mae) e a Federal Home Loan Mortgage Association (conhecida como Freddie Mac) ${ }^{4}$. Essas companhias privadas com ações negociadas em bolsa de valores, mas consideradas como "patrocinadas pelo governo" (Government Sponsored Enterprises - GSE), conseguiam se financiar a um custo bastante próximo ao do Tesouro americano e, simultaneamente, operar de forma mais alavancada que outras instituições financeiras, sustentando suas atividades com um patrimônio conjunto de apenas US\$ 71 bilhões. Isto é, esse patrimônio poderia ser consumido por um prejuízo relativamente baixo como proporção da carteira. Enquanto o preço das casas subia,

\footnotetext{
${ }^{2}$ De acordo com a Seção 13 (3) do Federal Reserve Act (1932), o banco central tem o poder de emprestar para qualquer instituição contra qualquer colateral, desde que declare que isto seja necessário, pois "circunstancias específicas o exigem".

${ }^{3}$ Com a propagação da crise de confiança, a Irlanda elevou a garantia aos depósitos, ao conceder, no dia 30 de setembro de 2008, garantia integral aos depósitos por um período de dois anos. Em reação à decisão irlandesa, o governo britânico ampliou o limite da garantia aos depósitos bancários para $£$ 50 mil. A concessão de garantia integral pelos governos da Alemanha e Dinamarca levou a União Europeia a aumentar o limite mínimo de garantia aos depósitos bancários de $€ 20$ mil para $€ 50$ mil para o conjunto dos 27 países membros. Seguindo os governos europeus, o FDIC elevou o limite de depósitos garantidos para US\$ 250.000 e passou a garantir por três anos aos novos débitos dos bancos e das instituições de poupança e holding companies - incluindo notas promissórias, commercial paper, empréstimos interbancários (Fundap, 2008).

${ }^{4}$ Para maiores informações sobre o sistema financeiro imobiliário americano, ver Cagnin (2007).
} 
esse risco parecia limitado. Com a queda do preço dos imóveis, dados em garantias dos empréstimos, que passaram a valer menos do que as dívidas (hipotecas) e a duplicação no patamar de inadimplência, as empresas ficaram diante da possibilidade de insolvência (desequilíbrio patrimonial), ou pelo menos sem capital para continuar operando (Torres Filho e Borça Jr., 2008).

A administração do presidente George W. Bush solicitou ao Congresso a aprovação de um pacote de ajuda para essas duas instituições, por meio de empréstimos e compra de ações. Por seu turno, o Fed anunciou, num comunicado separado, que lhes concederia empréstimos de curto prazo. A inédita ação estava ligada à magnitude dos passivos dessas companhias. A Fannie Mae tinha dívida total em torno de US\$ 800 bilhões, enquanto a da Freddie Mac alcançava US\$ 740 bilhões. Ademais, as duas companhias carregavam ou tinham dado garantias a títulos hipotecários no valor de US\$ 4,6 trilhões, o que representava 38\% dos créditos hipotecários nos EUA e 32\% de seu Produto Interno Bruto (PIB), estimado em US\$ 14,3 trilhões em junho de 2008. Complicando ainda mais a situação, parte significativa desses títulos tinha sido adquirida por bancos centrais estrangeiros. Em junho de 2008, a dívida total das agências federais americanas detida por estrangeiros somava US\$ 1,66 trilhão, sendo US\$ 1,1 trilhão em portfólios de credores oficiais e US\$ 557 bilhões em credores privados ${ }^{5}$. Em outras palavras, os títulos emitidos pela Fannie Mae e pelo Freddie Mac foram considerados para a aplicação das reservas internacionais como tão "sem riscos" quanto os títulos do Tesouro americano, com a vantagem de oferecer rendimentos um pouco mais elevados.

A falência do Lehman Brothers, em 15 de setembro de 2008, constituiu o ponto mais agudo da crise, que passou a apresentar contornos sistêmicos ${ }^{6}$. Ela acarretou a paralisação das operações interbancárias e a desconfiança dos investidores nos sistemas financeiros se espalhou, resultando em movimentos de pânico nos mercados de ações, de câmbio, de derivativos e de crédito, em âmbito global. A recusa das autoridades americanas em impedir a falência do Lehman Brothers foi seguida pela compra do Merrill Lynch pelo Bank of America, enquanto o Goldman Sachs e o Morgan Stanley obtiveram autorização para se transformarem em holding financeiras (financial holding companies), sujeitas às normas de Basileia, à supervisão do Fed e com acesso às operações de redesconto. Era o fim dos grandes bancos de investimento independentes de Wall Street.

Mas, não foram somente os bancos de investimento e as GSE que sofreram os impactos da crise. Nesse período, outras instituições financeiras não-bancárias

\footnotetext{
${ }^{5}$ De acordo com o Tesouro, os maiores detentores das dívidas das agências americanas eram a China e o Japão.

${ }^{6}$ Segundo Barros (2008): “quando quebrou, o banco de investimento Lehman Brothers tinha US\$ 650 bilhões em compromissos, contra um capital de US\$ 20 bilhões”. Ver também, Lehman's demise triggered cash crunch around globe, The Wall Street Journal, 29/10/2008.
} 
como hedge funds, fundos de investimento e seguradoras enfrentaram uma verdadeira "corrida bancária" contra o global shadow banking system na expressão de McCulley (2007b), ou de uma "corrida bancária contra não-bancos” segundo Kedroski (2007). Em movimentos reveladores da importância que os não-bancos adquiriram, o Fed e o Tesouro americano tiveram de estender a diversas dessas instituições o acesso às operações de redesconto - com a aceitação de títulos lastreados em crédito hipotecário - e a criação de linhas de crédito aos money market mutual funds ${ }^{7}$. O Banco da Inglaterra também adotou medidas semelhantes através de operações de swaps.

Os bancos universais também registraram prejuízos crescentes. As estimativas das perdas permaneceram incompletas e conflitantes ${ }^{8}$. A inadimplência começou a se espalhar para outras formas de crédito ao consumidor bem como a atingir devedores de crédito hipotecário considerados de menor risco que os subprime. Ademais, é preciso levar em conta que a maior parte dos empréstimos hipotecários subprime foi concedida com condições que tornavam as prestações iniciais baixas, mas que, passados um ou dois anos, as levavam a subir de forma acentuada. À medida que reconheciam novas perdas, os grandes bancos foram obrigados, repetidas vezes, a sair em busca de cada vez mais custosos aportes de capitais, em particular de fundos soberanos, para reforçar seus caixas de forma a voltar a se adequar aos acordos de Basileia9. Todavia, a falência do

\footnotetext{
${ }^{7}$ Até o momento, os hedge funds e os fundos de pensão não tiveram acesso às operações de resgate. A seguradora American International Group Inc. (AIG) recebeu empréstimos do Fed no valor de US\$ 182,5 bilhões, em troca de ações com direito a voto. Posteriormente, descobriu-se que tinha vendido proteção contra risco de crédito (CDS) no valor nocional de US\$2,7 trilhões no início de 2008. Posição reduzida para US\$ 1,5 trilhão em março de 2009 (Sterngold, 2009). As seguradoras de vida foram incluídas no Troubled Asset Relief Program (TARP) no início de abril de 2009 (Patterson et al., 2009).

${ }^{8}$ Uma das dificuldades residia na própria forma de contabilizar as perdas. Para uns, os bancos estavam maquiando balanços, escondendo prejuízos atrás de fórmulas matemáticas de avaliação de ativos mais complexos e sem liquidez a preços de mercado. Para outros, os bancos não deveriam mesmo marcar a mercado todas as perdas, pois não teriam como absorvê-las com o capital disponível. Ademais, a regra seria pró-cíclica, impondo a reprecificação dos balanços em momentos de aversão a risco. Em 2 de abril de 2009, a Financial Accounting Standards Board (Fasb) flexibilizou as normas de precificação de ativos e passivos a valores de mercado para as instituições financeiras (conhecida como FASB 157). Pela contabilidade do "valor justo", as demonstrações financeiras deveriam ser efetuadas pelos preços de mercado, exceto se as instituições provassem que alguns mercados estavam inativos ou enfrentando vendas desordenadas. Com o aprofundamento da crise, as negociações com muitos títulos foram interrompidas ou realizadas com preços que não refletiam seus valores. A flexibilização permitiu que as instituições oferecessem avaliações para esses títulos por meio de modelos internos de precificação, desde que os montantes, os modelos e os parâmetros utilizados fossem explicitados nas notas explicativas dos balanços contábeis.

${ }^{9}$ Além dos prejuízos em suas carteiras de crédito, novos problemas surgiram em função das sucessivas
quedas nas cotações dos títulos, trazendo à luz supostas falcatruas que haviam passado despercebidas
na euforia. Um dos casos envolveu títulos denominados auction rate security (ARS). Os bancos foram
acusados de ludibriar seus clientes, vendendo-os ativos considerados seguros, mesmo quando seus
} 
Lehman Brothers dificultou a obtenção de novos capitais pelos bancos. Houve a necessidade de grandes volumes de injeções de capital público nos bancos e garantias para emissões de novas dívidas. $\mathrm{Na}$ área euro, por exemplo, os recursos públicos disponibilizados para tentar restaurar a confiança do sistema financeiro somaram $€ 2$ trilhões, o equivalente a $22,5 \%$ do PIB regional (ver Tabela 1). Outros países - tais como Canadá, Coreia do Sul, Dinamarca, Emirados Árabes Unidos, Noruega, Suécia, Reino Unido etc. - efetuaram programas estimados em $€ 898,2$ bilhões (ver Tabela 2).

Tabela 1: Medidas para estimular os sistemas financeiros - área euro

\begin{tabular}{|c|c|c|c|c|c|c|}
\hline & $\begin{array}{c}\text { Injeção } \\
\text { de capital }\end{array}$ & $\begin{array}{l}\text { Garantia para } \\
\text { emissões de } \\
\text { novas dívidas }\end{array}$ & $\begin{array}{l}\text { Outros } \\
\text { (a) }\end{array}$ & $\begin{array}{c}€ \\
\text { bilhões }\end{array}$ & $\begin{array}{l}\% \text { do } \\
\text { PIB }\end{array}$ & Observações \\
\hline Alemanha & 80 & 400 & - & 480 & 20,0 & \\
\hline Áustria & 15 & 85 & - & 100 & 37,0 & \\
\hline Bélgica & 17,4 & - & - & 17,4 & 5,2 & $\begin{array}{l}\text { Inclui Dexia, Eth- } \\
\text { ias, Fortis e KBC }\end{array}$ \\
\hline Chipre & 2 & - & - & 2 & 12,8 & \\
\hline Eslovênia & - & 12 & 1 & 13 & 39,0 & \\
\hline Espanha & - & 200 & 50 & 250 & 23,8 & \\
\hline Finlândia & 4 & 50 & - & 54 & 30,1 & \\
\hline França & 24 & 320 & - & 344 & 18,0 & Inclui Dexia \\
\hline Grécia & 5 & 15 & 8 & 28 & 12,3 & \\
\hline Holanda & 36,8 & 200 & - & 236,8 & 41,6 & Inclui Fortis \\
\hline Irlanda & 10 & 400 & - & 410 & 215,1 & \\
\hline Itália & 12 & - & 40 & 52 & 3,4 & \\
\hline Luxemburgo & 2,9 & - & - & 2,9 & 8,0 & \\
\hline Portugal & 4 & 20 & - & 24 & 14,7 & \\
\hline Zona euro & 213 & 1.702 & 99 & 2.014 & 22,5 & \\
\hline
\end{tabular}

Fonte: BNP Paribas, Market Economics/Credit Strategy/Interest Rate Strategy, 19 January 2009.

Nota: a) Inclui compra de ativos. Exclui garantia aos depósitos bancários.

mercados tinham deixado de existir. Entre 7 e 8 de agosto de 2008, após investigações da Securities and Exchange Commission (SEC), o Citigroup e o UBS aceitaram resgatar ao par todos esses títulos, com um custo US\$ 7,5 bilhões para o Citigroup e de US\$ 19 bilhões para o UBS. O Merrill Lynch anunciou o desembolso de US\$ 10 bilhões para o mesmo fim, antes de um acordo com a SEC. Até 14 de agosto, os bancos haviam se comprometido a recomprar US\$ 48 bilhões em ARS. Outras instituições financeiras deverão seguir os mesmos procedimentos, colocando pressões adicionais em suas reservas (Chang, 2008). 
Tabela 2: Medidas para estimular os sistemas financeiros - outros países

\begin{tabular}{|c|c|c|c|c|c|c|c|}
\hline & $\begin{array}{c}\text { Injeção } \\
\text { de } \\
\text { capital }\end{array}$ & $\begin{array}{l}\text { Garantia para } \\
\text { emissões de } \\
\text { novas dívidas }\end{array}$ & $\begin{array}{l}\text { Outros } \\
\text { (a) }\end{array}$ & $\begin{array}{l}\text { Moeda } \\
\text { local } \\
\text { (bilhões) }\end{array}$ & $\begin{array}{c}€ \\
\text { bilhões }\end{array}$ & $\begin{array}{c}\% \text { do } \\
\text { PIB }\end{array}$ & Observações \\
\hline $\begin{array}{l}\text { Arábia } \\
\text { Saudita }\end{array}$ & $\$ 3$ & - & - & $\$ 3$ & 2,4 & 0,8 & \\
\hline Austrália & - & - & 8 & 8 & 4 & 0,7 & \\
\hline Canadá & - & 218 & 75 & 293 & 187,9 & 19,1 & \\
\hline Catar & $\$ 6$ & - & - & $\$ 6$ & 4,7 & 8,8 & \\
\hline $\begin{array}{l}\text { Coreia } \\
\text { do Sul }\end{array}$ & - & $\$ 100$ & $\$ 8,1$ & $\begin{array}{r}\$ \\
108,1\end{array}$ & 85,8 & 11,1 & \\
\hline Dinamarca & 100 & - & - & 100 & 13,4 & 5,9 & $\begin{array}{l}\text { Mais perdas } \\
\text { superiores a } \\
\text { DKK } 35 \text { bilhões } \\
\text { em passivos } \\
\text { bancários }\end{array}$ \\
\hline $\begin{array}{l}\text { Emirados } \\
\text { Árabes } \\
\text { Unidos }\end{array}$ & $\$ 19$ & - & - & $\$ 19$ & 14,7 & 9,6 & \\
\hline Hungria & $\$ 1,5$ & $\$ 1,5$ & - & $\$ 3,1$ & 2,3 & 2,2 & \\
\hline Noruega & - & - & 350 & 350 & 41 & 15,4 & \\
\hline $\begin{array}{l}\text { Reino } \\
\text { Unido }\end{array}$ & 50 & 250 & 50 & 350 & 385 & 25,0 & $\begin{array}{l}\text { Exclui Special } \\
\text { Liquidity } \\
\text { Scheme } \\
\text { (£ } 200 \text { bilhões) }\end{array}$ \\
\hline Suécia & 15 & 1.500 & - & 1.515 & 153 & 49,3 & \\
\hline Suíça & 6 & - & - & 6 & 4 & 1,0 & $\begin{array}{l}\text { Exclui } \\
\text { capitalização } \\
\text { do UBS }\end{array}$ \\
\hline Total & - & - & - & - & 898,2 & - & \\
\hline
\end{tabular}

Fonte: BNP Paribas, Market Economics/Credit Strategy/Interest Rate Strategy, 19/01/2009.

Nota: a) Inclui compra de ativos. Exclui garantia aos depósitos bancários.

Obs.: \$ - valores em dólar.

Os planos de resgate dos EUA atingiram US\$ 7,4 trilhões, incluindo o Troubled Asset Relief Program (US\$ 700 bilhões, gerido pelo Tesouro), segundo estimativa da Bloomberg (ver Tabela 3). Além disso, para enfrentar a desconfiança em seu sistema bancário, o Tesouro anunciou um Plano de Estabilização Financeira ( $F i$ nancial Stability Plan), em março de 2009. O plano prevê quatro componentes básicos: a) os balanços dos bancos passarão por avaliações cuidadosas (stress test) e as instituições que necessitarem de capital terão acesso a um novo programa 
patrocinado pelo Tesouro (Financial Stability Trust); b) o Tesouro, o Fed, a FDIC e o setor privado estabelecerão um Fundo de Investimento Público Privado, começando com US\$ 500 bilhões, podendo alcançar US\$ 1 trilhão. Esse fundo será destinado à compra dos ativos tóxicos ("ativos podres”); c) o Fed disponibilizará US\$ 1 trilhão para estimular a recuperação do crédito ao consumidor; d) US\$ 50 bilhões em fundos federais serão direcionados para tentar abrandar a execução de hipotecas residenciais e amortecer o impacto da crise imobiliária.

Tabela 3: Planos de resgate dos EUA (US\$) - novembro de 2008

\begin{tabular}{l|c|c}
\hline & Destinado & Aplicado \\
\hline Federal Reserve & 4,5 trilhões & 1,8 trilhão \\
\hline Federal Deposit Insurance Corp. (FDIC) & 1,5 trilhão & 139 bilhões \\
\hline Treasury Department & 1,1 trilhão & 597 bilhões \\
\hline Federal Housing Administration (FHA) & 300 bilhões & 300 bilhões \\
\hline Total & 7,4 trilhões & 2,83 trilhões \\
\hline
\end{tabular}

Fonte: http://www.bloomberg.com/apps/data?pid=avimage\&iid=iOYrUuvkygWs.

\section{AS PRINCIPAIS CARACTERÍSTICAS DO GLOBAL SHADOW BANKING SYSTEM}

Chama a atenção o fato de que os casos mais agudos de fragilidade financeira registrados nessa crise envolveram instituições financeiras que não tinham, pela norma existente antes de sua eclosão, acesso aos seguros de depósitos e/ou às operações de redesconto das autoridades monetárias. Essa característica é própria daquilo que vem sendo denominado de global shadow banking system. Esse termo foi empregado, pela primeira vez por Paul McCulley (2007), diretor executivo da maior gestora de recursos do mundo, a Pimco. Note-se que, entre as medidas adotadas pelo Fed e por outros bancos centrais, encontra-se a abertura do acesso às operações de redesconto - com a aceitação de títulos lastreados em crédito hipotecário e outros - a essas diversas instituições que não podiam utilizá-las como os bancos de investimentos e as GSE. Entretanto, essas medidas revelaram-se insuficientes para conter o "desmanche" do global shadow banking system, pois, buscando sobreviver, venderam avidamente os ativos para os quais ainda existia mercado, provocando acentuada desvalorização de seus preços.

Esse sistema se desenvolveu ao longo das últimas décadas tendo como pano de fundo as complexas relações que se estabeleceram entre instituições financeiras nos opacos mercados de balcão. Desde o final da década de 1980, esses mercados têm sido amplamente utilizados para a negociação de derivativos financeiros, por meio dos quais as instituições financeiras tanto podiam buscar cobertura de seus riscos de câmbio, de juros e de preços de mercado de outros ativos como especular sobre a tendência desses preços ou efetuar operações de arbitragem. Enquanto se 
restringiam às negociações desses ativos, as relações entre o sistema bancário propriamente dito e as instituições integrantes do global shadow banking system resumiam-se aos créditos que o primeiro concedia ao segundo e ao fato que era frequente a realização de operações entre ambos.

Mas, quando estes mercados de balcão passaram a negociar derivativos de crédito e títulos oriundos da securitização dos créditos concedidos pelos bancos comerciais, combinados com algum tipo de derivativos que recebem o nome genérico de "produtos estruturados", o sistema bancário e o global shadow banking system se interpenetraram de modo quase inextrincável. Os bancos buscaram diversas formas de retirar os riscos de seus balanços com o objetivo de alavancar suas operações sem ter de reservar os coeficientes de capital requeridos pelos acordos de Basileia (Cintra \& Prates, 2008, e Freitas, 2008). Fizeram isso de diversas formas: adquirindo proteção contra os riscos de crédito nos mercados de derivativos, securitizando créditos com rendimento atrelado aos reembolsos devidos pelos tomadores de empréstimos e criando diversos veículos especiais de investimento (Special Investments Vehicles ou SIV), conduits ou SIV-lites ${ }^{10}$. Mas, somente puderam transferir esses riscos porque outros agentes se dispuseram a assumir a contraparte dessas operações, ou seja, assumir riscos contra um retorno que, à época, parecia elevado.

As outras instituições financeiras, que não estavam sujeitas às normas prudenciais dos Acordos de Basileia, passaram a ter um acesso considerado altamente remunerador às operações de crédito. Bastava captar recursos no mercado de títulos de curto prazo e adquirir os títulos de longo prazo securitizados com lastro em créditos emitidos pelos bancos e/ou vender a estes proteção contra os riscos de crédito para reproduzir "sinteticamente" uma operação de crédito. Dessa forma, os mercados de balcão passaram a constituir o palco de negociação tanto de ativos como de passivos das instituições financeiras. Enquanto tal, eles se transformaram em fonte de funding e de investimentos para as instituições financeiras que deles participavam.

\section{Captar no curto prazo e emprestar no longo}

Os bancos concedem empréstimos com os recursos que recebem de seus depositantes e com o capital próprio. Mas os bancos criam depósitos - moeda bancária escritural - ao conceder crédito (Keynes, 1930). Emitem também títulos de dívidas para obter recursos e conceder novos financiamentos (Chick, 1994). Em geral, os

\footnotetext{
${ }^{10}$ De acordo com FMI (2007, p. 18), esses veículos especiais tendem a se diferenciar pelo tamanho e composição do ativo e passivo. Em geral, os conduits tendem a ser maiores e menos arriscados, com ativos de até US\$ 1,4 trilhão; os SIV, intermediários, com ativos em torno de US\$ 400 bilhões; e os SIV-lites, com ativos menores, cerca de US\$ 12 bilhões, mas de elevado risco. A carteira de ativos das SVI-lites, que opera com alta alavancagem ( 40 a 70 vezes dependendo do colateral), tende a ser composta por $96 \%$ de hipotecas residenciais securitizadas (RMBS) e $4 \%$ de CDO. Todos têm algum mecanismo de liquidez total ou parcial garantido pelas instituições patrocinadoras.
} 
empréstimos concedidos possuem prazos mais longos do que os depósitos ou as dívidas. Em decorrência da criação de depósitos e do descasamento de prazos, os sistemas tendem a ser altamente instável, sujeitos a processos de euforia ou pessimismo e a corridas bancárias. Por essa razão, foram desenvolvidas instituições para garantir os depósitos, para atuar como "emprestadoras de última instância", para regular e supervisionar o sistema bancário.

Na última década, verificaram-se dois movimentos simultâneos e complementares. Em primeiro lugar, os bancos submetidos à regulação buscaram retirar riscos de seus balanços - de forma a não ter de manter parcelas elevadas de capitais próprios em reserva, como requerem os Acordos de Basileia ${ }^{11}$ - e aumentaram extraordinariamente sua alavancagem. Em segundo lugar, uma grande variedade de instituições evoluiu no sentido de desempenhar um papel semelhante ao dos bancos tradicionais sem estarem incluídas na estrutura regulatória existente e, portanto, sem dispor das requeridas reservas em capital.

Como sugerido, os bancos sujeitos à regulação lançaram mão de diversos instrumentos para retirar os riscos de crédito de seus balanços, como forma de enfrentar a concorrência. Eles estiveram na origem do surgimento e da forte expansão dos derivativos de crédito, por meio dos quais podem comprar proteção para os riscos de crédito de suas carteiras de empréstimos. Valeram-se, igualmente, dos chamados "produtos estruturados" - ABS, RMBS, CMBS, CDO etc. - instrumentos resultantes da combinação entre um título representativo de um crédito debêntures, bônus, títulos de crédito negociáveis, hipotecas, dívida de cartão de crédito etc. - e o conjunto dos derivativos financeiros (futuros, termo, swaps, opções e derivativos de crédito) qualquer que seja seu ativo subjacente. Por meio de sua utilização, esses bancos empacotaram os créditos concedidos, os submeteram às agências de classificação de riscos e lançaram títulos sobre eles cujos rendimentos são proporcionais ao fluxo de caixa gerado pela quitação das prestações dos créditos. Os títulos estruturados eram divididos em diversas tranches com riscos e retornos diferenciados. A estrutura de distribuição dos juros ficou conhecida como "queda d'água" (interest waterfall), porque a água tem de encher o primeiro reservatório ou tranche mais sênior para posteriormente começar a preencher os outros (mezzanine e equity). A porção mais arriscada dentre elas (equity) - a que assume os riscos de inadimplência iniciais - e que recebeu o nome de lixo tóxico (toxic waste) acabou muito frequentemente ficando entre os ativos dos SIV.

Os bancos sujeitos à regulação criaram pessoas jurídicas - Special Investment Vehicles (SIV), conduits ou SIV-lites - que adquiriam esses títulos estruturados, com recursos provenientes da emissão de títulos de crédito de curto prazo (asset-backed commercial papers). Segundo o Wall Street Journal, os SIV tinham emitido US\$1,5 trilhão em commercial papers, até meados de 2007 (Reilly e Mollenkamp, 2007). Essas pessoas jurídicas não eram tecnicamente propriedades dos bancos nem seus

\footnotetext{
${ }^{11}$ Para uma discussão sobre os impactos dos Acordos de Basileia, ver Guttmann (2006) e Freitas (2008).
} 
resultados figuravam nos balanços, constituindo parte relevante do global shadow banking system junto com diversos outros novos intermediários financeiros. Dessa forma, os bancos universais obtinham mais recursos, além de receitas (taxas, comissões), que lhes permitiram conceder novos créditos e elevar seus lucros, num processo de crescente alavancagem.

Não estando habilitados a obter recursos de depositantes, os SIV, bem como os demais novos intermediários financeiros, foram buscá-los no mercado de capitais, sobretudo, emitindo títulos de curto prazo (commercial papers). Eles utilizaram esses recursos de curto prazo para assumir a contraparte das operações dos bancos, seja no mercado de derivativos, vendendo proteção contra riscos de crédito, seja nos produtos estruturados, adquirindo os títulos emitidos pelos bancos com rentabilidade vinculada ao reembolso dos créditos concedidos. Tornaram-se, dessa forma, participantes do mercado de crédito, obtendo recursos de curto prazo com os quais financiavam operações de longo prazo (hipotecas de 30 anos, por exemplo), atuando como quase-bancos (Kregel, 2008; Guttmann \& Plihon, 2008; Freitas \& Cintra, 2008).

Existe uma grande variedade de participantes do global shadow banking system. Os principais são os bancos de investimentos, seguidos pelos hedge funds, pelos fundos de investimentos, pelas seguradoras, pelos fundos de pensão e pelas GSE. Os bancos de investimento multiplicaram os hedge funds sob sua administração, abrindo espaço em suas carteiras para produtos e ativos de maior risco e montaram estruturas altamente alavancadas. Os bancos universais também passaram a patrocinar hedge funds, fornecendo-lhe crédito para suas operações (inclusive compra de "produtos estruturados") bem como emulando suas estratégias de negócios. Como afirma Blackburn (2008, p. 90): “os bancos de Wall Street não somente patrocinam hedge funds, mas cada vez mais passam a se parecer com eles à medida que usam sua posição de intermediários primários (prime brokers) para alavancar suas apostas e buscar arbitragens" ${ }^{12}$. As GSE, com garantia do setor público, representaram o espelho dos veículos "fora de balanço" do setor financeiro privado altamente alavancado. Como afirma Belluzzo (2008): "em um ambiente de estabilidade e de rendimentos em queda, a busca de ganhos mais alentados levou aos píncaros as relações entre o valor dos ativos carregados nas carteiras e o capital próprio das instituições. Equações e letras gregas são mera retórica pseudocientífica para justificar as trapalhadas financeiras. (...) Quando esses agentes são surpreendidos por movimentos bruscos e não antecipados de preços, as perdas estimadas obrigam à liquidação de posições para a cobertura de margem, ampliando desmesuradamente o risco de mercado e o risco de liquidez". Sem dispor de reservas de capital, com ativos cuja liquidez desapareceu a partir da eclosão da crise em junho de 2007 - fazendo com que seu preço deixasse de ter cotação - e

\footnotetext{
12 Sobre a emulação das estratégias dos hedge funds pelos bancos universais, ver Cintra e Cagnin (2007).
} 
confrontadas ao expressivo encolhimento de sua fonte de funding, muitas dessas instituições acabaram em péssima situação financeira, senão à beira da falência.

\section{Uma teia opaca de inter-relacionamento financeiro internacional}

Os prejuízos das instituições participantes do global shadow banking system acabaram, em parte, achando seu caminho para os balanços dos bancos. Alguns bancos (como o Citigroup) tinham incluído opções de venda (que dão a seu detentor a possibilidade de revender o ativo a um preço predeterminado) nos títulos de securitização de crédito. Essas opções foram exercidas, obrigando os bancos a recomprar os ativos no momento em que sua liquidez desapareceu e seus preços tenderam a zero. Os diversos SIV tinham a garantia dos bancos que os criaram. Em outros casos, esses novos intermediários possuíam linhas de crédito pré-aprovadas com bancos universais que, amplamente utilizadas, passaram a apresentar baixíssimas possibilidades de ser reembolsadas.

Existe outro importante vínculo entre os balanços dos bancos e as instituições do global shadow banking system. Eles têm interagido nos mercados de derivativos de balcão e, em particular, nos de derivativos de crédito, tornando-se contrapartes uns dos outros. Ora, as características próprias desses instrumentos fazem com que esses mercados constituam um jogo de soma zero, em que as perdas de uns correspondem aos ganhos de outros, se excetuarmos os custos de transação. No agregado dos mercados de derivativos, só se pode ganhar, os valores perdidos por outros participantes.

Os produtos negociados no mercado de balcão não têm cotação oficial. Os preços são livremente acordados entre as partes. Ademais, contrariamente aos ativos e derivativos negociados em mercados organizados, os preços dos ativos de balcão não são transparentes, à medida que não são tornados públicos. Essa falta de transparência nos preços nos mercados de balcão, notadamente nos que apresentam baixa liquidez ou em montagens complexas e sofisticadas, pode impedir ou dificultar sua avaliação no decorrer do período em que a posição é mantida.

A prática contábil de mark-to-market (ajustar a preços de mercado), adotada conforme as recomendações dos organismos internacionais de supervisão e regulamentação, de forma a permitir uma avaliação do valor das posições, pode não ter referência clara e ser apenas aproximativa no que se refere aos derivativos de balcão, envolvendo consultas a outros intermediários ou cálculos segundo modelos matemáticos complexos. No final da década de 1990, alguns casos de elevados prejuízos em mercados de balcão somente foram detectados nos seus vencimentos e não durante o decurso da operação e estiveram na origem de diversos processos judiciais contra as instituições financeiras que intermediaram as operações. $\mathrm{Na}$ atual crise, o problema ressurgiu de forma mais aguda. No final de 2006, o Financial Accounting Standards Board, que regulamenta as informações contábeis das instituições financeiras americanas, introduziu nova classificação dos ativos financeiros para efeito 
de apuração de seus preços. O nível um compreendia os ativos cujos preços eram formados em mercados líquidos; o nível dois incluía os ativos cujos preços dependiam de modelos com inputs baseados em preços de ativos negociados em mercados; o nível três envolvia ativos cujos mercados eram menos líquidos e cujos preços só podiam ser obtidos usando-se modelos matemáticos. No nível dois, encontrava-se boa parte dos derivativos de balcão, enquanto os ativos lastreados em hipotecas ou outros tipos de crédito e investimentos em private equity estavam no nível três.

Essas normas contábeis, que deveriam garantir a estabilidade e a transparência do sistema, contribuíram para aumentar sua volatilidade e falta de transparência, provocando com isso uma crise de liquidez acompanhada de uma crise de confiança. Os "produtos estruturados" e os derivativos de crédito, que haviam permitido a realização de lucros recordes, se transformaram, para retomar a expressão do Warren Buffett, em "armas de destruição em massa” (English, 2003). O risco sistêmico de um desmoronamento do sistema bancário como um todo se delineou. Com efeito, os ativos de nível um só representavam algo próximo de $9 \%$ dos ativos das instituições financeiras americanas, enquanto os de nível dois e três constituíam os restantes três quartos. Assim, é difícil negar que essas instituições financeiras detinham ativos pouco líquidos em excesso, que a crise financeira se encarregou de reprecificar a patamares próximos de zero. O mesmo investidor Warren Buffett declarou à revista Fortune que essas instituições "estão marcando a modelo (martto-model) ao invés de marcar a mercado. A recente derrocada nos mercados de dívida transformou este processo em uma marcação a mito".

Em seu depoimento ao Senado americano, em 3 de abril de 2008, Ben Bernanke, presidente do Fed, reconheceu que a decisão de intervir no Bear Stearns decorreu do fato que "o sistema financeiro é extremamente complexo e este banco de investimentos participava amplamente em vários mercados extremamente relevantes. Sua súbita falência acarretaria uma vasta e caótica liquidação das posições nesses mercados, o que abalaria seriamente a confiança dos agentes. Essa falência levantaria igualmente dúvidas sobre as posições financeiras dos milhares de contrapartes do Bear Stearns e, quem sabe, das demais instituições com perfis de negócios semelhantes" (Bernanke, 2008a). Essa declaração apontou que os problemas que suscitaram a intervenção do Fed, numa instituição financeira que não estava sob sua supervisão, ultrapassavam o clássico too big to fail. Eles podiam melhor ser caracterizados como too interconnected to fail; ou seja, dificuldades graves em bancos que participam de "mercados relevantes" passam a suscitar a intervenção de "última instância", mesmo quando esta não esteja nas "regras do jogo" institucional, porque sua falência provocaria efeito dominó nesses mercados, com elevado risco sistêmico. As palavras de Bernanke indicaram também que os problemas do Bear Stearns eram mais amplos que o crédito hipotecário e abrangiam o conjunto de suas posições nesses "mercados relevantes" ${ }^{13}$. Em boa parte, tais mercados

\footnotetext{
${ }^{13}$ Cf. Blackburn (2008, p. 96): "o resgate do Bear Stearns foi duro para os acionistas, mas não para os detentores de títulos emitidos por ele e nem para suas contrapartes”.
} 
eram os mercados de ativos e de derivativos de balcão, somente neles que existia o risco de contraparte "aos milhares". A posição declarada do Bear Stearns nesses mercados de derivativos alcançava, em final de dezembro de 2007, um valor nocional, isto é, o valor que os ativos teriam no vencimento, de US\$ 13 trilhões. A decisão das autoridades monetárias americanas de permitir a falência do Lehman Brothers tornou-se ainda mais incompreensível, já que esse banco detinha igualmente importantes posições nesses mesmos mercados.

Nos mercados organizados em bolsas de valores, a transferência dos ganhos e perdas é organizada e garantida pelas câmaras de compensação. Nos mercados de balcão, a inexistência dessas câmaras de compensação coloca em evidência um elevado risco de inadimplência da contraparte perdedora. Dessa forma, aumentam os riscos potenciais dos derivativos de balcão em relação aos negociados em mercados organizados. A introdução, no início deste milênio, dos derivativos de crédito e sua acentuada expansão ampliaram fortemente os riscos agregados presentes nos mercados de balcão. Esses derivativos nasceram da constatação do crescente fosso entre técnicas sofisticadas de gestão dos riscos de juros, câmbio e de mercado e dos modos mais tradicionais disponíveis para a gestão dos riscos de crédito (securitização, diversificação de carteira, garantias colaterais, limites operacionais etc.). Utilizando os mecanismos já existentes de swaps, os derivativos de crédito permitiram que os bancos retirassem riscos de seus balanços, ao mesmo tempo em que as instituições financeiras do global shadow banking system passaram a ter novas formas de assumir exposição aos riscos e rendimentos do mercado de crédito. Os mais utilizados são os swaps de inadimplência de crédito (credit default swaps, CDS) que transferem o risco de crédito entre o agente que adquire proteção e a contraparte que vende proteção ${ }^{14}$. Por esse mecanismo, o detentor de uma carteira de crédito compra proteção (paga um prêmio) ao vendedor de proteção. Em troca, esse assume, por um prazo predeterminado, o compromisso de efetuar o pagamento das somas combinadas nos casos especificados em contrato, que vão de inadimplência ou falência à redução da classificação de crédito ou outros eventos que possam causar queda do valor da carteira. O risco de contraparte é mais acentuado nos derivativos de crédito, já que os riscos das operações atingem o principal das posições, ao contrário dos demais derivativos em que os riscos das operações situam-se na margem.

Não sendo "originadoras" de crédito, as instituições do global shadow banking system assumiram, sobretudo, a posição vendida nesses derivativos, reproduzindo "sinteticamente" a exposição ao crédito e a seus rendimentos. Os dados apurados pelo Bank for International Settlements (BIS) em junho de 2008 indicaram: a) o crescimento generalizado dos derivativos de balcão que alcançaram US $\$ 683,7$ trilhões em valores nocionais (praticamente 11 vezes o PIB mundial) e US\$20,3 trilhões

\footnotetext{
${ }^{14}$ Sobre os derivativos de crédito e seus modelos de precificação, ver Magalhães (2008) e Yokoyama (2007).
} 
em valores brutos de substituição a preço de mercado $^{15}$, ou seja, um aumento de $28,7 \%$ em relação ao semestre anterior (ver Tabela 4); b) uma elevação extremamente acelerada dos valores nocionais e valores brutos de mercado dos derivativos de crédito (CDS), entre junho de 2007 e junho de 2008, num período em que os negócios com produtos estruturados ligados ao crédito foram praticamente inexistentes. Os valores nocionais dos derivativos de crédito atingiram US $\$ 57,3$ bilhões, e os valores brutos de substituição a preço de mercado, US\$ 3,2 trilhões.

A crise oriunda do aumento da inadimplência no crédito hipotecário americano e seus desdobramentos provocaram um forte aumento nos prêmios dos CDS que aparecem claramente nestes dados: para um aumento de 34,6\% no valor nocional dos CDS, entre junho de 2007 e junho de 2008, registrou-se uma alta de $339,9 \%$ no seu valor bruto de substituição a preço de mercado (ver Tabela 4). As instituições que tinham assumido posições vendidas nos CDS amargaram altíssimos prejuízos em função desta alta dos prêmios.

Ademais, a elevação dos valores nocionais dos derivativos de crédito, num período tão conturbado, indica, por um lado, que prêmios mais elevados atraíram novos especuladores dispostos a assumir os riscos de crédito para os quais muitos procuravam cobertura. Por outro lado, o reconhecimento do papel crucial desses instrumentos alavancados levou a uma rara convergência entre os reguladores e os representantes das instituições financeiras para a criação de uma câmara de compensação que cubra margens de garantia dos participantes, para minimizar os riscos de contraparte, e traga alguma transparência às posições em aberto e à distribuição de riscos. Algumas empresas privadas estão se "candidatando" para assumir esta função de câmara de compensação. No processo de concorrência entre elas, em novembro de 2008, novos dados começaram a emergir, trazendo alguma luz aos opacos mercados de balcão. Embora parciais, esses dados apontaram que, após a compensação das posições, verificou-se forte redução dos compromissos líquidos assumidos e, por conseguinte, dos volumes de riscos presentes. Eles tornaram manifesto o fato que, na inexistência de uma câmara de compensação, qualquer liquidação antes do vencimento das operações é contada duas vezes, uma referente à posição original e outra à sua liquidação antecipada, até o vencimento.

\footnotetext{
${ }^{15}$ Há dois métodos de agregação dos derivativos. O primeiro é pelo valor nocional, que equivale ao valor do ativo subjacente. O segundo é denominado "valores brutos de mercado", que corresponde ao custo de substituição de todos os contratos aos preços atuais de mercado. Apenas para explicitar, os volumes nocionais nos mercados organizados de derivativos são bastante inferiores aos registrados nos mercados de balcão: US\$ 20,1 trilhões nos mercados futuros e US\$ 39,7 trilhões nos mercados de opções, somando US\$ 59,8 trilhões em dezembro de 2008.
} 
Tabela 4: Estoque de derivativos negociados nos mercados de balcão - US\$ bilhões

\begin{tabular}{|c|c|c|c|c|c|c|c|c|}
\hline \multirow[b]{2}{*}{ Instrumento } & \multicolumn{4}{|c|}{ Valor nocional } & \multicolumn{4}{|c|}{ Valor bruto de mercado } \\
\hline & $\begin{array}{l}2006 \\
\text { dez. }\end{array}$ & 2007 jun. & 2007 dec. & 2008 jun. & $\begin{array}{c}2006 \\
\text { dez. }\end{array}$ & $\begin{array}{l}2007 \\
\text { jun. }\end{array}$ & $\begin{array}{l}2007 \\
\text { dec. }\end{array}$ & $\begin{array}{l}2008 \\
\text { jun. }\end{array}$ \\
\hline Total & 414.845 & 516.407 & 595.341 & 683.725 & 9.691 & 11.140 & 15.813 & 20.353 \\
\hline $\begin{array}{l}\text { Mercado de } \\
\text { Câmbio }\end{array}$ & 40.271 & 48.645 & 56.238 & 62.983 & 1.266 & 1.345 & 1.807 & 2.262 \\
\hline $\begin{array}{l}\text { Reporting } \\
\text { Dealers (a) }\end{array}$ & 15.532 & 19.173 & 21.334 & 24.845 & 438 & 455 & 594 & 782 \\
\hline $\begin{array}{l}\text { Outras Inst. } \\
\text { Financei. }\end{array}$ & 16.023 & 19.144 & 24.357 & 26.775 & 521 & 557 & 806 & 995 \\
\hline $\begin{array}{l}\text { Inst. não- } \\
\text { financeiras }\end{array}$ & 8.716 & 10.329 & 10.548 & 11.362 & 307 & 333 & 407 & 484 \\
\hline $\begin{array}{l}\text { Merc. de } \\
\text { Taxas de } \\
\text { Juros }\end{array}$ & 291.582 & 347.312 & 393.138 & 458.304 & 4.826 & 6.063 & 7.177 & 9.263 \\
\hline $\begin{array}{l}\text { Reporting } \\
\text { Dealers (a) }\end{array}$ & 127.432 & 148.555 & 157.245 & 188.982 & 1.973 & 2.375 & 2.774 & 3.554 \\
\hline $\begin{array}{l}\text { Outras Inst. } \\
\text { Financei. }\end{array}$ & 125.708 & 153.370 & 193.107 & 223.023 & 2.223 & 2.946 & 3.786 & 4.965 \\
\hline $\begin{array}{l}\text { Inst. não- } \\
\text { financeiras }\end{array}$ & 38.441 & 45.387 & 42.786 & 46.299 & 630 & 742 & 617 & 745 \\
\hline $\begin{array}{l}\text { Mercado de } \\
\text { Ações }\end{array}$ & 7.488 & 8.590 & 8.469 & 10.177 & 853 & 1.116 & 1.142 & 1.146 \\
\hline $\begin{array}{l}\text { Reporting } \\
\text { Dealers (a) }\end{array}$ & 2.537 & 3.118 & 3.011 & 3.479 & 290 & 405 & 398 & 376 \\
\hline $\begin{array}{l}\text { Outras Inst. } \\
\text { Financei. }\end{array}$ & 4.295 & 4.473 & 4.598 & 5.496 & 452 & 549 & 578 & 616 \\
\hline $\begin{array}{l}\text { Inst. não- } \\
\text { financeiras }\end{array}$ & 656 & 999 & 861 & 1.203 & 111 & 161 & 166 & 154 \\
\hline $\begin{array}{l}\text { Mercado de } \\
\text { Commodity }\end{array}$ & 7.115 & 7.567 & 8.455 & 13.229 & 667 & 636 & 1.899 & 2.209 \\
\hline Ouro & 640 & 426 & 595 & 649 & 56 & 47 & 70 & 68 \\
\hline Outras & 6.475 & 7.141 & 7.861 & 12.580 & 611 & 589 & 1.829 & 2.142 \\
\hline $\begin{array}{l}\text { Derivativos } \\
\text { de crédito }\end{array}$ & 28.650 & 42.580 & 57.894 & 57.325 & 470 & 721 & 2.002 & 3.172 \\
\hline Simples & 17.879 & 24.239 & 32.246 & 33.334 & 278 & 406 & 1.143 & 1.889 \\
\hline Múltiplo & 10.771 & 18.341 & 25.648 & 23.991 & 192 & 315 & 859 & 1.283 \\
\hline Outros & 39.740 & 61.713 & 71.146 & 81.708 & 1.609 & 1.259 & 1.788 & 2.301 \\
\hline $\begin{array}{l}\text { Exposição de } \\
\text { crédito bruta }\end{array}$ & - & - & - & - & 2.036 & 2.672 & 3.256 & 3.859 \\
\hline
\end{tabular}

Fonte: BIS, Semiannual OTC derivatives statistics at end-June 2007.

Nota: a) Nas estatísticas do BIS, reporting dealers são os grandes bancos internacionais e os agentes chamados de broker-dealer nos EUA. Nenhuma outra instituição financeira não-bancária está incluída nessa rubrica. 
No seu conjunto, os mercados de derivativos de balcão são extremamente opacos, tanto no que concerne ao nível de preços das operações, como no que diz respeito ao volume e aos riscos das posições assumidas pelos participantes. Sua característica de instrumento virtual que espelha, por diversos mecanismos, os riscos e retornos de um ativo financeiro permite que, através das atividades de especulação e arbitragem, esses riscos e retornos sejam replicados inúmeras vezes. No que concerne à sua utilização como instrumento de cobertura de riscos, ela é eficiente no nível microeconômico. Mas, no tocante à economia como um todo, é necessário considerar que a quantidade de riscos presentes no sistema não se reduz com a utilização dos derivativos financeiros para efeitos de cobertura de riscos (hedge). Eles só alteram sua distribuição. Para que os eventuais benefícios macroeconômicos das operações de hedge possam manifestar-se numa situação de crise, é necessário que, ao serem transferidos, os riscos tenham se diluído entre um grande número de pequenos especuladores ou tenham se concentrado em carteiras fortes, capazes de suportar os prejuízos deles resultantes. Caso contrário, numa demonstração suplementar da difícil interligação entre os aspectos micro e macroeconômicos, os mercados de derivativos terão contribuído para o agravamento da instabilidade original, desencadeando inadimplências em cascata que podem originar um risco sistêmico (Farhi, 2002). Como a negociação desses derivativos acaba formando uma intrincada teia de créditos e débitos entre as instituições financeiras, os episódios de volatilidade elevada das cotações resultam num repentino aumento da percepção de riscos de crédito suplementares, num montante consolidado e numa distribuição desconhecidos. Tais episódios costumam provocar interrupções das linhas de crédito interbancárias mais bruscas e acentuadas do que no período em que predominavam as negociações de derivativos nos mercados organizados. A atual crise tem confirmado as análises anteriores dos impactos macroeconômicos das inovações financeiras em períodos de fragilidade financeira. Mas ela o faz em escala ampliada em função da forte elevação do volume negociado de derivativos e produtos estruturados, da ampliação dos números e tipos de participantes além do surgimento e expansão dos derivativos de crédito.

\section{RESPOSTAS AO APROFUNDAMENTO DA CRISE}

A primeira resposta para esta complexa e amarga situação que configurou um risco sistêmico, em que riscos financeiros e bancários impactaram a economia real e reforçaram as tendências recessivas, foi a política monetária lassa (redução dos juros nos EUA, Reino Unido, área euro, Japão, Canadá, China, Índia e inúmeros países emergentes) e os empréstimos de liquidez (troca de títulos públicos por recursos líquidos e troca de hipotecas ilíquidas por títulos públicos) pelo Fed e outros bancos centrais. A segunda resposta foi a ampliação dos acordos de troca de moedas pelo Fed e outros 14 bancos centrais a fim de facilitar o processo de desalavancagem global. A terceira resposta foi a política fiscal expansionista, seja por meio de uma ampliação dos gastos públicos, seja por meio de aportes do Tesouro ame- 
ricano para as GSE, para os contribuintes e para as famílias de baixa renda com dívidas hipotecárias (e outros orçamentos fiscais na área euro, no Japão, no Reino Unido, na China e em inúmeros países emergentes).

A quarta resposta aponta na direção de reformas nas regras de supervisão e regulação existentes. Essa alternativa foi sinalizada por Bernanke (2008b), no seminário do Fed em Jackson Hole. Para o presidente do banco central americano, os reguladores geralmente se "focalizam nas condições financeiras de instituições isoladas", enquanto seria necessário analisar suas interconexões e considerar "potenciais riscos sistêmicos e pontos de fragilidade”. Mas a tarefa se anuncia difícil. Dada a interpenetração internacional de ativos e passivos dos bancos e instituições do global shadow banking system, os reguladores teriam de realizar a unificação, inclusive acima das fronteiras nacionais, dos organismos encarregados de sua implementação e execução, de forma a aplicar as mesmas regras para todas as instituições financeiras e ser capaz de avaliar o conjunto dos riscos presentes no sistema. Esse foi um dos pontos para os quais a reunião do G20, de março de 2009, não conseguiu encontrar consenso. Ademais, deveriam instituir normas de funcionamento para os mercados de balcão, pouco habituados a cumprir qualquer tipo de regulamentação. Esse pode ser um longo e espinhoso debate, mormente se ocorrer no âmbito do Comitê de Basileia (Basel Committee for Banking Supervision, BCBS). Com efeito, para ser frutífera, a discussão deveria abandonar um dos princípios básicos que têm norteado, nas últimas décadas, os acordos internacionais de supervisão e regulação: a governança corporativa e a gestão de riscos pelos bancos evoluíram a tal ponto que se pode considerar que suas decisões são as mais eficientes para evitar a ocorrência de episódios que podem desembocar em risco sistêmico. A crise revelou o quanto esse princípio estava equivocado.

Por essa razão chama a atenção o relatório divulgado pelo Counterparty Risk Management Policy Group III (CRMPG III, 2008), formado pelo grupo de assessoria da Presidência dos Estados Unidos para mercados financeiros (President's Working Group on Financial Markets), reunindo os principais bancos que operam nos EUA. Seu objetivo era prover uma resposta do setor privado à crise de crédito de 2007 e 2008, de forma a fornecer subsídios e a complementar outros trabalhos realizados tanto pelo setor público como por entidades privadas como o Institute for International Finance (IIF, 2008) ${ }^{16}$. Entre as sugestões apresentadas destacam-se: a) criação de uma câmara de compensação para os derivativos de balcão; b) exigências que as contrapartes em certas operações no mercado de balcão sejam "suficientemente sofisticadas para entender as operações e seus riscos"; c) mudanças na contabilização dos ativos lastreados em crédito - incluindo os já existentes - que deixariam de ser considerados "fora de balanço" e passariam a ser incluídos nos balanços. Essa última recomendação provocou frissons na alta finança internacional porque levaria a um aumento do capital regulatório das instituições. Mas, afirmou o relatório: "por mais custosas que venham a ser essas reformas, esse

${ }^{16}$ Para outras propostas, ver Group of Thirty (2009) e Carvalho e Kregel (2009). 
custo será minúsculo se comparado às centenas de bilhões de dólares em créditos em liquidação que as instituições financeiras tiveram de enfrentar nos últimos meses, para não falar das distorções e dos deslocamentos econômicos ocasionados pela crise".

Tanto o relatório do CRMPG III (2008) como o do IIF (2008) constituem exemplos típicos dos chamados mecanismos de "autorregulação" das instituições financeiras. Esses mecanismos envolvem a tomada de medidas voluntárias. Nesse sentido, sua implementação e sua eficácia dependeriam da persistência das grandes instituições. Somente elas poderiam fazer com que essas medidas voluntárias se tornassem normas a serem seguidas por todos os que quisessem negociar com elas.

\section{REFERÊNCIAS BIBLIOGRÁFICAS}

BARROS, Luiz Carlos M. Muito pouco, muito tarde..., Folha de S.Paulo, São Paulo, 19 de setembro de 2008, p.B2.

BELluZZO, Luiz G. M. Salvação de moribundos, Carta Capital, Ano XIV, n.505. São Paulo, 23 de julho de 2008, p.54-55.

BERNANKE, Ben S. Developments in the financial markets. Testimony of Mr Ben S Bernanke, Chairman of the Board of Governors of the US Federal Reserve System, before the Committee on Banking, Housing, and Urban Affairs, US Senate, Washington DC, April 3, 2008 a.

BERNANKE, Ben S. Reducing Systemic Risk. At the Federal Reserve Bank of Kansas City's Annual Economic Symposium, Jackson Hole, Wyoming, August 22, 2008 b.

BLACKBURN, R. The Subprime crisis, New Left Review, n. 50, London, Mar./Apr. 2008, p.63-106.

BORIO, C. The financial turmoil of 2007-?: a preliminary assessment and some policy considerations, BIS Working Papers, n.251. Basle: BIS/Monetary and Economic Department, March 2008.

CRMPG III. Containing systemic risk: the road to reform. The Report of the Counterparty Risk Management Policy Group III, August 6, 2008. Available at - http://www.crmpolicygroup.org.

CAGNIN, Rafael F. O mercado imobiliário e a recuperação econômica dos EUA após 2002. Campinas: IE/Unicamp (Dissertação de Mestrado), 2007.

CARVALHO, Fernando J. C. \& KREGEL, J. Crise financeira e déficit democrático. Rio de Janeiro: Ibase (Instituto Brasileiro de Análises Sociais e Econômicas).

CHANG, J. Bancos devem recomprar US\$ 48 bi em ARS, Financial Times de Nova York, reproduzido em Valor Econômico, São Paulo, 15 de agosto de 2008, p.C2.

CHICK, V. A evolução do sistema bancário e a teoria da poupança, do investimento e dos juros, Ensaios FEE, Ano 15, n.1, Porto Alegre, p.9-23, 1994.

CINTRA, Marcos A. M. \& PRATES, Daniela M. Basel II in question: the unfolding of the US real estate crisis. Paper preparado para o Workshop on Financial Liberalization and Global Governan$c e$, Rio de Janeiro, Instituto de Economia da Universidade Federal do Rio de Janeiro (UFRJ), com patrocínio do IBase e Fundação Ford, 8 e 9 de maio de 2008.

CINTRA, Marcos A. M. \& CAGNIN, Rafael F. Evolução da estrutura e da dinâmica das finanças norte-americanas. Econômica, Rio de Janeiro, v.9, n.1, p.89-131, 2007.

ENGLISH, S. Apocalypse is nigh, Buffett tells Berkshire faithful, The Daily Telegraph, March 3, 2003.

FARHI, Maryse. Novos instrumentos e práticas na finança internacional. Campinas: IE/Unicamp e São Paulo: Fapesp (Pesquisa de Pós-doutoramento), 2002.

FREITAS, Jean. Estabilidade financeira em países em desenvolvimento e Acordos de Basiléia. Campinas: IE/Unicamp (dissertação de mestrado), 2008. 
FREITAS, M. Cristina P. de \& CINTRA, Marcos A. M. Inflação e deflação de ativos a partir do mercado imobiliário americano, Revista de Economia Política, vol.28, n.3 (111), São Paulo, Editora 34, p.414-433, 2008.

FUNDAP. Panorama e perspectiva das economias avançadas: sob o signo da crise. São Paulo: Grupo de Conjuntura da Fundação do Desenvolvimento Administrativo do Estado de São Paulo, nov./2008.

GROUP of Thirty (The). Financial reform: a framework for financial stability. Washington, DC, 2009.

GUTTMANN, R. Basiléia II: uma nova estrutura de regulação para a atividade bancária global, in: MENDONÇA, Ana Rosa R. de \& ANDRADE, Rogério P. de (Org.) Regulação bancária e dinâmica financeira: evolução e perspectivas a partir dos Acordos de Basiléia. Campinas: IE/Unicamp, p.177-212, 2006.

GUTTMANN, Robert \& PLIHON, Dominique. Consumer debt at the center of finance-led capitalism. Paris, janeiro/2008 (mimeo). [Revista Economia e Sociedade, número especial, vol.17. Campinas: IE/Unicamp, dez./2008].

IIF. Final Report of the IIF Committee on Market Best Practices: Principles of Conduct and Best Practice Recommendations. Washington, DC: Institute of International Finance (IIF), July 2008.

IMF. Global Financial Stability Report. Washington, D.C. International Monetary Fund, April 2008.

KEDROSKY, P. The First non-bank bank run, September 3, 2007. Available at - http://paul.kedrosky. com/archives/2007/09/03/the_first_nonba.html.

KEYNES, J. M. (1930) Treatise on money. The Collected Writings of John Maynard Keynes, vol. V e VI. Moggridge, D. E. (Org.). London: Macmillan, 1971.

KREGEL, J. Minsky's cushions of safety: systemic risk and the crisis in the U.S. subprime mortgage market. Public Policy Brief, n.93, The Levy Economics Institute of Bard College, January 2008.

MAGALHÃES, Ana Laura D. P. Derivativos de crédito: análise e relação com a crise das hipotecas subprime. Campinas: IE/Unicamp (monografia), 2008.

McCULLEY, P. Credit, markets, and the real economy: is the financial system working? A reverse Minsky journey, Global Central Bank Focus, April 2008a. Available at - http://www.pimco.com/ LeftNav/Featured+Market+Commentary/FF/2008/Global+Central+Bank+Focus+4-08+Credit+ Markets+and+the+Real+Economy.htm.

McCULlEY, P. The Paradox of deleveraging, Global Central Bank Focus, July 2008b. Available at http://media.pimco-global.com/pdfs/pdf/GCB\%20Focus\%20July\%2008_web.pdf?WT.cg_ n=PIMCO-US\&WT.ti=GCB\%20Focus\%20July\%2008_web.pdf.

McCULLEY, P. Teton Reflections, Global Central Bank Focus, August/September 2007b. Available at - http://www.pimco.com/LeftNav/Featured+Market+Commentary/FF/2007/GCBF+August-+September+2007.htm.

McCULLEY, P. Comments on housing and the monetary transmission mechanism, September 1, 2007b. Available at - http://www.econbrowser.com/archives/2007/09/comments_on_hou.html.

PATTERSON, Scott; SOLOMON, Deborah \& SCISM, Leslie. U.S. to offer aid to life insurers, The Wall Street Journal, April 8, 2009. Available at -http://online.wsj.com/article/ SB123914741752198971.html.

REILLY, D. \& MOLLENKAMP, C. Conduits' in need of a fix, The Wall Street Journal, August 30, 2007.

STERNGOLD, J. AIG's shrinking swaps unit may suffer more losses (Update2), Bloomberg, April 15 2009. Available at - http://www.bloomberg.com/apps/news?pid=email_en\&sid=ao30aE_ZsShQ.

TORRES Filho, Ernani T. \& BORÇA Jr., Gilberto R. A crise do subprime ainda não acabou. Visão do Desenvolvimento, n.50. Rio de Janeiro: BNDES, 2008.

YOKOYAMA, Gustavo T. Uma abordagem sobre os derivativos de crédito e sua aplicação no gerenciamento de risco de crédito. Campinas: IE/Unicamp (monografia), 2007. 